\title{
Caspase 8 and maspin are downregulated in breast cancer cells due to CpG site promoter methylation
}

Yanyuan Wu ${ }^{1,2}$, Monica Alvarez ${ }^{1}$, Dennis J Slamon ${ }^{2}$, Phillip Koeffler ${ }^{2,3}$, Jaydutt V Vadgama ${ }^{1,2^{*}}$

\begin{abstract}
Background: Epigenetic changes associated with promoter DNA methylation results in silencing of several tumor suppressor genes that lead to increased risk for tumor formation and for progression of the cancer.

Methods: Methylation specific PCR (MSP) and bisulfite sequencing were used for determination of proapoptotic gene Caspase 8 (CASP8) and the tumor suppressor gene maspin promoter methylation in four breast cancer and two non-tumorigenic breast cell lines. Involvement of histone $\mathrm{H} 3$ methylation in those cell lines were examined by CHIP assay.

Results: The CpG sites in the promoter region of CASP8 and maspin were methylated in all four breast cancer cell lines but not in two non-tumorigenic breast cell lines. Demethylation agent 5-aza-2'-deoxycytidine (5-aza-dc) selectively inhibits DNA methyltransferases, DNMT3a and DNMT3b, and restored CASP8 and maspin gene expression in breast cancer cells. 5-aza-dc also reduced histone H3k9me2 occupancy on CASP8 promoter in SKBR3cells, but not in MCF-7 cells. Combination of histone deacetylase inhibitor Trichostatin A (TSA) and 5-aza-dc significant decrease in nuclear expression of Di-methyl histone H3-Lys27 and slight increase in acetyl histone H3Lys9 in MCF-7 cells. CASP8 mRNA and protein level in MCF-7 cells were increased by the 5-aza-dc in combination with TSA. Data from our study also demonstrated that treatment with 5-FU caused a significant increase in unmethylated CASP8 and in CASP8 mRNA in all 3 cancer lines.
\end{abstract}

Conclusions: CASP8 and maspin expression were reduced in breast cancer cells due to promoter methylation. Selective application of demethylating agents could offer novel therapeutic opportunities in breast cancer.

\section{Background}

Aberrant DNA methylation has been recognized as one of the most common molecular alterations in human neoplasia. Hypermethylation of gene-promoter regions is being revealed as one of the most frequent event that causes loss of gene function. DNA methylation usually occurs at a cytosine associated with CpG sites [1]. DNA (cytosine-5)-methyltransferase (DNA-MTase) catalyzes this reaction by adding a methyl group from S-adenosyl-L-methionine to the fifth carbon position of the cytosine [1]. Methylation of CpG sites in the promoter region of the genes is known to transcriptionally repress these genes [2]. CpG sites of a large number of genes

\footnotetext{
* Correspondence: javadgam@cdrewu.edu

'Division of Cancer Research and Training, Department of Internal Medicine, Charles R. Drew University of Medicine and Science, (1731 East 120th Street) Los Angeles, CA (90059), USA
}

that are unmethylated in normal tissue are methylated in human cancers, such as breast, ovarian, colon, and prostate cancers $[3,4]$. Methylation at the promoter region of specific genes depends on tumor type. For example, the mismatch repair gene hMLH1 is silenced by hypermethylation more frequently in colorectal, endometrial, and gastric tumors; while the BRCA1 is methylated in breast and ovarian tumors [5-8]. Recent studies have suggested that CPG methylation of certain genes may be associated with HER2 receptor overexpression and/or hormone status in breast cancer [8,9]. It is unclear as to which breast cancer specific genes are transcriptionally silenced and if their silencing is associated with failure in treatment and decrease in diseasefree survival (DFS).

CASP8 is an important initiator of apoptosis [10]. Absent or downregulation of CASP8 could cause

\section{Biomed Central}


resistance to apoptosis and is correlated with unfavorable disease outcome, such as in childhood medulloblastoma and neuroblastoma $[11,12]$. The absence or downregulation of CASP8 may be due to epigenetic changes. Studies have also indicated that methylation and demethylation of maspin promoter may regulate maspin gene expression and that reduced maspin expression is associated with cancer progression [13].

In the current study we used methylation specific PCR (MSP), and bisulfite sequencing to determine the methylation status of these two genes. We examined the mechanisms associated with transcriptional silencing of CASP8 and maspin by promoter methylation using realtime PCR and by restoring the methylated genes back to their unmethylated status using the demethylating agent, 5-aza-2'-deoxycytidine; TSA (Trichostatin A), inhibitor of histone deacetylase; and chemotherapeutic agent $5-\mathrm{Fu}$ (5-Fluorouracil).

\section{Methods}

\section{Cells and culture}

The breast cancer cells with varying tissue subtypes selected for our methylation studies were: MCF-7 (ER positive and HER2/neu negative); MDA-MB231 (ER negative and HER2/neu negative); SKBR3 (ER negative and HER2/neu positive); HCC1937 (ER negative, HER2/ neu negative and BRCA1 mutated); non-tumorigenic breast epithelial cells (MCF12A), and non-tumorigenic breast fibroblast cells (MCF10). These cell lines were purchased from American Type Culture Collection (Rockville, MD), and unless otherwise stated, the cells were grown and maintained in DMEM/F12 (Fisher Scientific, CA) containing 10\% FCS (Invetrogen), $2 \mathrm{mM}$ glutamine, 50 units $/ \mathrm{ml}$ penicillin and $50 \mu \mathrm{g} / \mathrm{ml}$ streptomycin (Fisher Scientific, CA).

\section{5-aza-2'-deoxycytidine (5-aza-dc) and Trichostatin A (TSA)} treatment

The cells were growing in culture medium until $80 \%$ confluence; 5 HM 5-aza-dc was added and incubated for 3 to 6 days. The medium containing 5 -aza-dc was refreshed every 2 days. For combination treatment cells were first treated with $0.3 \mu \mathrm{M}$ TSA in combination with $5 \mu \mathrm{M} 5$-aza-dc for 2 days and then TSA was removed from culture medium. Treatment with $5 \mu \mathrm{M} 5$-aza-dc was continued for 1 more day.

Bisulfite modification and Methylation Specific PCR (MSP) Bisulfite conversion of genomic DNA was carried out using Zymo EZ DNA Methylation-Gold ${ }^{\mathrm{TM}}$ kit (D5005, Zymo Research Corp, Orange, CA) according to the manufacture's instructions. This process converts unmethylated cytosine residues to uracil, while methylated cytosine residues remain unchanged. Bisulfite modified DNA was used as a template, and then MSP was performed to determine the methylation status of
CASP8 and maspin. The primer sequences for MSP are as follows:

(a) CASP8, 5'-TGTTGTTTGGGTAACGTATCGA-3' (methylated forward),

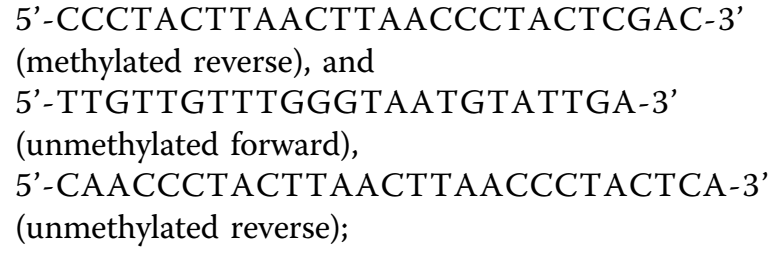

(b) maspin, 5'-ATTTTATCGAATATTTTATTTT TCGG-3' (methylated forward),

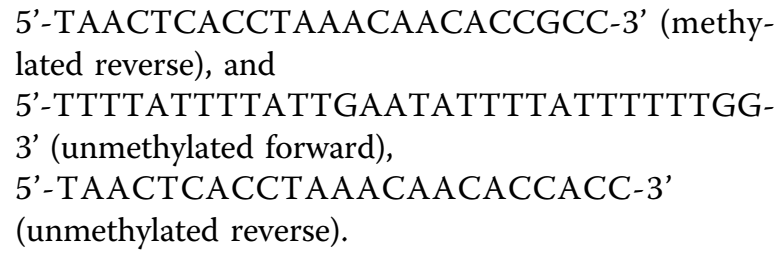

The primers for MSP were designed using MethPrimer [14] according to the sequences provided by Panomics (Fremont, CA). The cover regions were shown in Additional file 1, Figure S1. PCR conditions were as follows: an initial denaturation at $95^{\circ} \mathrm{C}$ for 5 min was followed by 40 cycles at $94^{\circ} \mathrm{C}$ for $30 \mathrm{~s}, 50^{\circ} \mathrm{C}$ for $30 \mathrm{~s}$, and $72^{\circ} \mathrm{C}$ for $45 \mathrm{~s}$ and a final extension at $72^{\circ} \mathrm{C}$ for 7 min.

\section{Bisulfite sequencing for CASP8 promoter}

Bisulfite modified DNA (described above) was amplified by two primer sets. The primer sequences were as follows: P1-CASP8 (nt -744 to nt -466), 5'-GGTGG TGGGTGTTTGTAGTTTTAGT-3' (forward) and 5'CCATCCTTAACCATATTCTCCAATTTA-3' (reverse); P2-CASP8 (nt -486 to nt +51), 5'-TAGATTTTTTGTA AGAAAGAATGGTAT-3' (forward) and 5'-ACAAAA AAACAAAATCTAATCTCC-3' (reverse). PCR conditions were as follows: an initial denaturation at $95^{\circ} \mathrm{C}$ for 5 min was followed by 40 cycles of $94^{\circ} \mathrm{C}$ for $30 \mathrm{~s}, 52^{\circ} \mathrm{C}$ for $30 \mathrm{~s}$, and $72^{\circ} \mathrm{C}$ for $45 \mathrm{~s}$ and a final extension at $72^{\circ} \mathrm{C}$ for $7 \mathrm{~min}$. The PCR products were purified with QIAquick PCR purification kit (\#28104, QIAGEN), and then sent to Retrogen Inc (San Diego, CA) for sequencing. The primers for bisulfite sequencing were designed using MethPrimer [14]. The sequence was used to design the bisulfate sequence primers were as same as the sequence used to design primers for MSP. The specific cover regions for each primer site have been demonstrated in Additional file 1.

\section{Quantitative real-time PCR (Q-PCR)}

Total RNA from cultured cells was isolated by using RNeasy micro kit (\#74004, QIAGEN) according to the 
manufacture's instructions, and cDNA was synthesized by reverse transcription (RT) with ThermoScript ${ }^{\mathrm{Tm}} \mathrm{RT}$ PCR system (Invitrogen) according to the manufacture's instructions. Q-PCR analysis was performed with iCycle iQ real-time PCR detection system (Bio-Rad Lab, Hercules, CA) using SYBR Green Master Mix (\#204143, QIAGEN). The primers used were as follows: (a) CASP8, 5'-CCAGAGACTCCAGGAAAAGAGA-3' (forward) and 5'-GATAGAGCATGACCCTGTAGGC-3' (reverse). (b) maspin, 5'-AGATGGCCACTTTGAGAACATT-3' (forward) and 5'-GGTTTGGTGTCTG TCTTGTTGA-3' (reverse). (c) housekeeping control gene, $18 \mathrm{~s}$, 5'-GATCCATTGGAGGGCAAGTC-3' (forward) and 5'-TCCCAAGATCCAACTACGAG-3' (reverse). Reactions were characterized during cycling when amplification of the PCR product was first detected $\left(C_{t}\right)$. The target message and the housekeeping gene, $18 \mathrm{~s}$, in breast cancer and non-tumorigenic cell lines, were quantified by measuring $C_{t}$. The relative level of target messages in cells was normalized on the basis of its $18 \mathrm{~s}$ content by taking the difference of threshold cycles between target gene and $18 \mathrm{~s}$. Using non-tumorigenic breast cancer cells or untreated breast cancer cells as reference, the level of CASP8 and maspin in each sample was normalized with the corresponding reference by taking the difference between threshold cycles. Final results were expressed as $\mathrm{N}$-fold difference in target gene expression relative to the reference.

Immunobloting and Immunofluorescence (IF)

For immunoblot analysis cells were lysed in $1 \times$ lysis buffer $(20 \mathrm{mM}$ Tris pH 7.5; $150 \mathrm{mM} \mathrm{NaCl} ; 1 \mathrm{mM}$ EDTA; 1 mM EGTA; 1\% Triton X-100; 2.5 mM sodium pyrophosphate; $1 \mathrm{mM} \beta$-glycerolphosphate; $1 \mathrm{mM}$ $\mathrm{Na}_{3} \mathrm{VO}_{4} ; 1 \mu \mathrm{g} / \mathrm{ml}$ leupeptin; $0.1 \mathrm{mM}$ PMSF) and protein concentration was measured using BCA dye (Pierce). Total protein $(50 \mu \mathrm{g})$ from cell lysates was resolved on SDS-PAGE followed by transfer to nitrocellulose membrane. The membranes were incubated with antibodies specific against Dnmt1 (IMG-261A, IMGENEX), Dnmt2 (IMG-281, IMGENEX), Dnmt3a (IMG-268A, IMGENEX), Dnmt3b (IMG-184A, IMGENEX), and caspase-8 (\#9746, Cell Signaling) according to manufacturer's instruction. Detection of antigen-bound antibody was performed with the enhance chemiluminescence reagent. For immunofluorescence analysis cells $\left(2 \times 10^{4}\right.$ / each) were mounted by cytospin on polylysine coated glass slides and fixed with $4 \%$ paraformaldehyde for 15 min followed by $100 \%$ ice-cold acetone for $10 \mathrm{~min}$ at $4^{\circ}$ C. To detect caspase- 8 protein expression immunofluorescence analysis was performed with cleaved caspase-8 antibody (\#9496, Cell Signaling) followed by incubation with anti-goat IgG-FITC (Santa Cruz) for $30 \mathrm{~min}$ in dark and mounted with DAPI mounting medium (Vector Labs). The cells with positive staining were counted in five different areas and adjusted with total number of cells. To analyze histone $\mathrm{H} 3$ methylation and acetylation status in MCF-7 cells double immunofluorescence analysis was performed with antibodies against Di-Methyl Histone H3 (Lys27) (\#9755, Cell Signaling) or Acetyl Histone H3 (Lys9) (\#9671, Cell Signaling) followed by $\beta$-actin antibody (A1975, Sigma-Aldrich). FITC-conjugated secondary antibodies were used to label Di-Methyl Histone H3 (Lys27) and Acetyl Histone H3 (Lys9). The $\beta$-actin was labeled with Tex-red-conjugated secondary antibody. After mounting, the cells were viewed under a fluorescence microscope.

\section{CHIP assay}

Cells were fixed with formaldehyde (1\% final concentration) to cross-link protein to DNA at room temperature for $10 \mathrm{~min}$ after treated with or without 5 -aza-dc $(5 \mu \mathrm{M}$, 3 days), and then incubated with glycine $(0.125 \mathrm{M}$ final concentration) for $5 \mathrm{~min}$ to stop the cross-linking. Soluble chromatin was prepared as described previously [15]. The chromatin was then diluted 1:10 with dilution buffer $(0.01 \%$ SDS, $1.1 \%$ Triton X-100, 1.2 mM EDTA, $16.7 \mathrm{mM}$ Tris- $\mathrm{HCl}, 167 \mathrm{mM} \mathrm{NaCl}$ and a protease inhibitor cocktail set (CalBiochem)), and subjected to immunoprecipitation with anti-dimethylated histone H3 lysine 9 (H3K9me2) antibody (\#9753, Cell signaling). Preimmune serum (Santa Cruz) was also used as a control. The chromatin and antibodies were incubated overnight at $4^{\circ} \mathrm{C}$. Chromatin/antibody complexes were recovered by adding $30 \mu \mathrm{l}$ of protein A/G Plus-agarose beads (Santa Cruz) and incubating at $4^{\circ} \mathrm{C}$ for $2 \mathrm{~h}$. The beads were sequentially washed for $10 \mathrm{~min}$ each in $1 \mathrm{ml}$ of low salt, high salt and $\mathrm{LiCl}$ immune complex wash buffer. Immunocomplexes were eluted off the beads by incubation with $300 \mu \mathrm{l}$ of $1 \%$ SDS and $50 \mathrm{mM}$ $\mathrm{NaHCO}_{3}$. The eluent was incubated at $65^{\circ} \mathrm{C}$ for $5 \mathrm{~h}$ or overnight to reverse the formaldehyde-induced proteinDNA cross-links. The DNA was extracted with phenol and chloroform. Extracted DNA was resuspended in 100 $\mu \mathrm{l}$ of TE buffer and real time PCR was performed by using Bio-Rad thermal cycler with CASP8 primers: forward 5'GGT GCC TGT AGT CCC AGC TAC TC3' and reverse 5'CCT AGA CCC TCC CCT GTT CTG TC3'. For input DNA, the chromatin preparation without incubated with antibodies was subjected to real time PCR.

\section{Results}

Promoter methylation on CASP8, and maspin resulted in decrease mRNA and protein expression

First, we determined the promoter methylation status in four breast cancer and one non-tumorigenic breast cell lines by MSP. We then examined if the promoter methylation would silence or decrease the gene or protein expression for CASP8 and maspin in different 
breast cancer and non-tumorigenic breast cells, and asked whether the 5-aza-cd treatment would reverse the methylation and change the mRNA expression of these genes. Results from MSP showed that CASP8 promoter was methylated in breast cancer cells, MCF-7, MB231, SKBR3, and HCC1937; but not in non-tumorigenic breast cells, MCF-10 (Figure 1A). The CASP8 promoter methylation resulted in the gene silence and lack of CASP8 in those breast cancer cells. CASP8 mRNA level were decreased significantly in all four breast cancer cells compared to non-tumorigenic breast cells, MCF-10 (Figure 1B). All four breast cancer cell lines, MCF-7, MB231, SKBR3 and HCC1937, lacked protein expression of caspase-8 (Figure 1C). Bisulfite sequence analysis demonstrated the position of the methylated $\mathrm{CpG}$ sites of CASP8 in different breast cancer cells (Figure 1D).

The mRNA level of maspin was decreased in MCF-7 cells; it was undetectable in MB231 and SKBR3 and remained high level in HCC1937 compared to MCF10 cells (Figure 2A). Consistent with the mRNA expression, results from MSP demonstrated that the maspin promoter in MCF-7, MB231 and SKBR3 were methylated (Figure $2 \mathrm{~B})$.

\section{Effect of 5-aza dc on DNA methylation}

Next, we examined if the mRNA expression of CASP8, and maspin could be restored by demethylating the target genes. We treated MCF-7, SKBR3, and MB231 with $5 \mu \mathrm{M} 5$-aza-dc for 3 days and performed RT-Q-PCR. Figure 3A confirms that gene expression of CASP8 in MB231, SKBR3, and HCC1937 cells can be restored with 5 -aza-dc treatment. The protein expression of CASP8 in MB231, SKBR3, and HCC1937 was also restored with 5 -aza-dc treatment (Figure 3B). The gene and protein expression of CASP8, however, were not restored with 5-aza-dc treatment for 3 days in MCF-7 cells (Figure 3A and 3B).

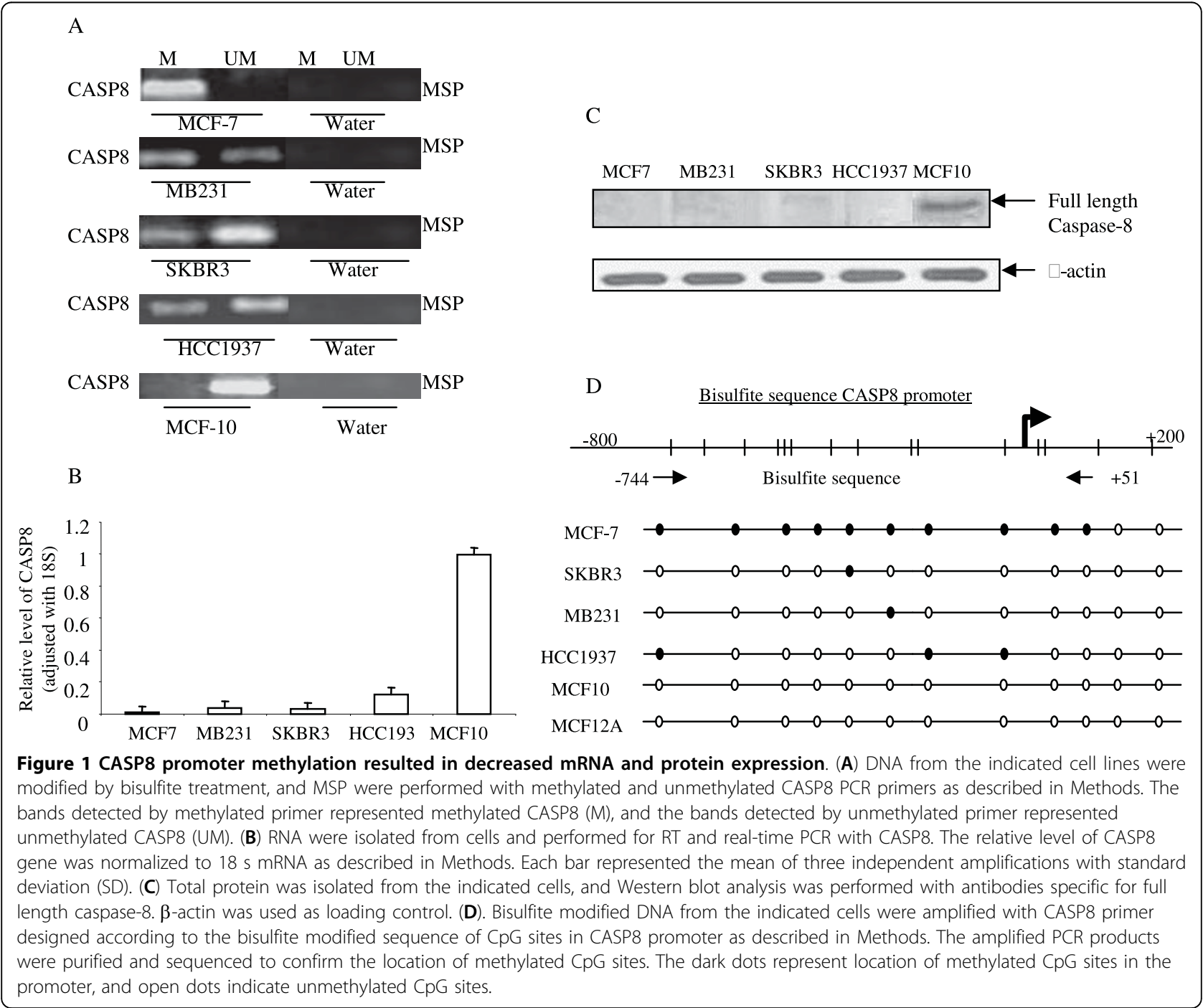


A
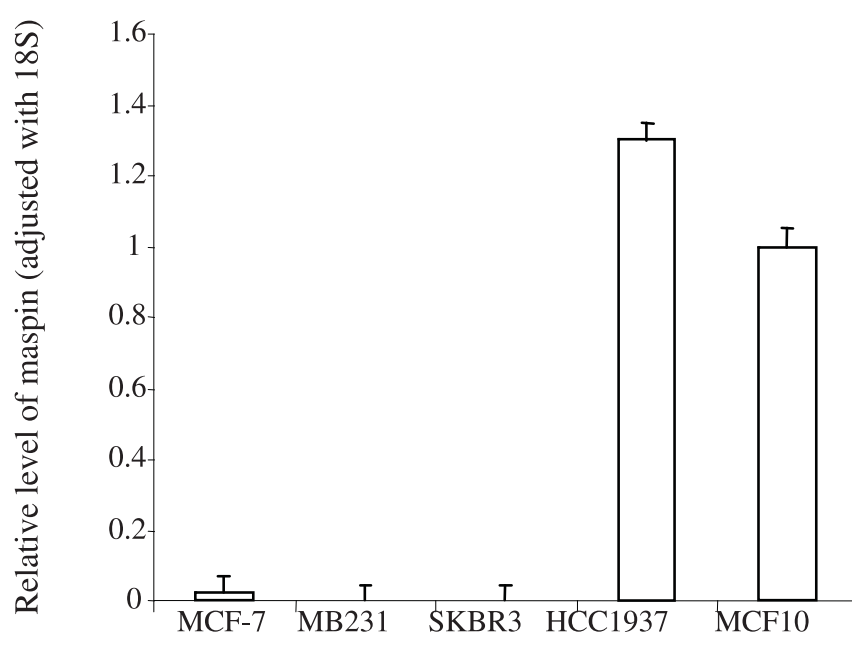

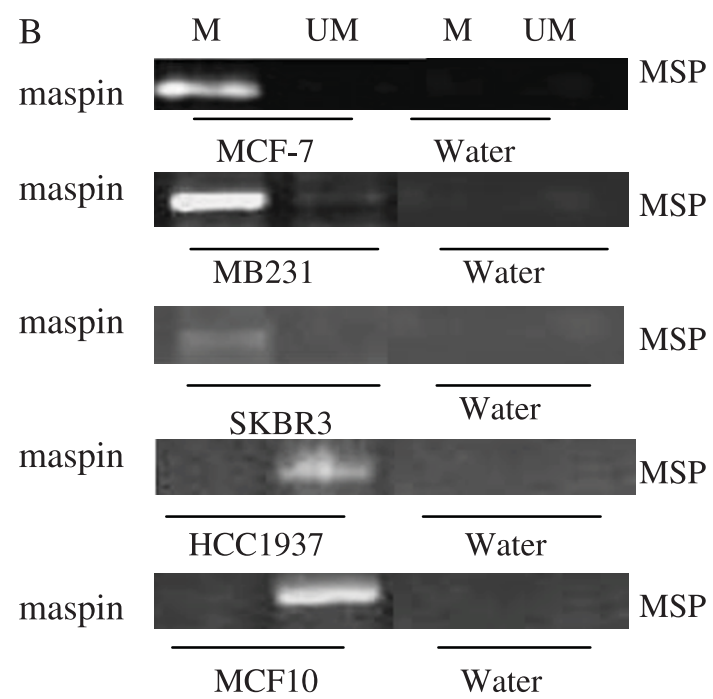

Figure 2 Maspin promoter methylation resulted in decreased mRNA and protein expression. (A) RNA were isolated from cells and performed for RT and real-time PCR with maspin primers. The relative level of the maspin gene was normalized to $18 \mathrm{~s}$ as described in Methods. Each bar represented the mean of three independent amplifications with standard deviation (SD). (B) DNA from the indicated cell lines were modified by bisulfite treatment, and MSP were performed with methylated and unmethylated maspin PCR primers as described in Methods. The bands detected by methylated primer represented methylated maspin (M), and the bands detected by unmethylated primer represented unmethylated maspin (UM).

To further confirm our hypothesis that loss of CASP8 in breast cancer cells may be due to promoter methylation, we performed MSP, which detected methylation of CpG sites of CASP8 in 5-aza-dc untreated breast cancer cells, MCF-7, MB231, SKBR3, and HCC1937 but not in MCF10 (Figure 3C). MSP also detected unmethylated CASP8 in MB231, SKBR3, and HCC1937 untreated cells (Figure 3C). However, as shown in Figure 3C, 5-aza-dc treatment completely demethylated the CASP8 promoter in MB231, SKBR3, and HCC1937 cells. In contrast, after treatment with 5-aza-dc, MSP detected a weak band of unmethylated CASP8 in MCF-7 cells. A good amount of methylated CASP8 still remained methylated after 5-aza-dc treatment in MCF-7 cells (top panel of Figure 3C). To determine the optimal time for treatment with 5-aza-dc to induce demethylation of CASP8 in MCF-7, cells were treated with 5-aza-dc from 3 to 6 days. MSP and RT-Q-PCR were used to assess the extent of demethylation. There were no significant changes in CASP8 promoter methylation as well as in mRNA expression after 3 days treatment (data not shown). However, after four days of treatment with 5aza-dc, we did see some restoration of unmethylated CASP8. The CASP8 mRNA expression also increased further after four days of treatment.

Taken together, the results from MSP confirmed that the loss of CASP8 gene and protein expression in these breast cancer cells resulted from CASP8 promoter methylation. Results also confirmed that CASP8 gene and protein can be restored by demethylation in selected breast cancer cells. Bisulfite sequencing analysis further demonstrated the position of demethylation of CASP8 related to restoring CASP8 gene and protein levels in 5-aza-dc treated cells (Figure 3D).

5 -aza-dc treatment also reactivated gene expression of maspin in MCF-7, MB231, and SKBR3 (Figure 3E). MSP confirmed that the reactivated maspin gene expression with 5-aza-dc treatment was consistent with demethylation on maspin promoter (Figure 3F). The CpG sites on maspin promoter in HCC1937 cells were not methylated; hence, we did not perform RT-Q-PCR and MSP for maspin on HCC1937 cell treated with 5-aza-dc. The increased gene expression following demethylation suggested that methylation-dependent transcriptional silencing may cause decreased expression or even total loss of CASP8 and maspin in breast cancer cells.

\section{Effect of 5-aza-dc on DNA Methyltransferases}

Since, 5-aza-dc (inhibitor of DNA methyltransferase) treatment did not demethylate CASP8 promoter region, we examined if 5-aza-dc was able to inhibit DNMTs (DNA methyltransferases). Figure 4A shows that 5-azadc treatment did not inhibit DNMT1, DNMT3a and DNMT3b in MCF-7 cells. However, it did inhibit DNMT3a and DNMT3b in MDAMB231 and BT474 (ER positive and HER2 positive) breast cancer cells. We did not detect DNMT2 in any of the cell lines tested. In 


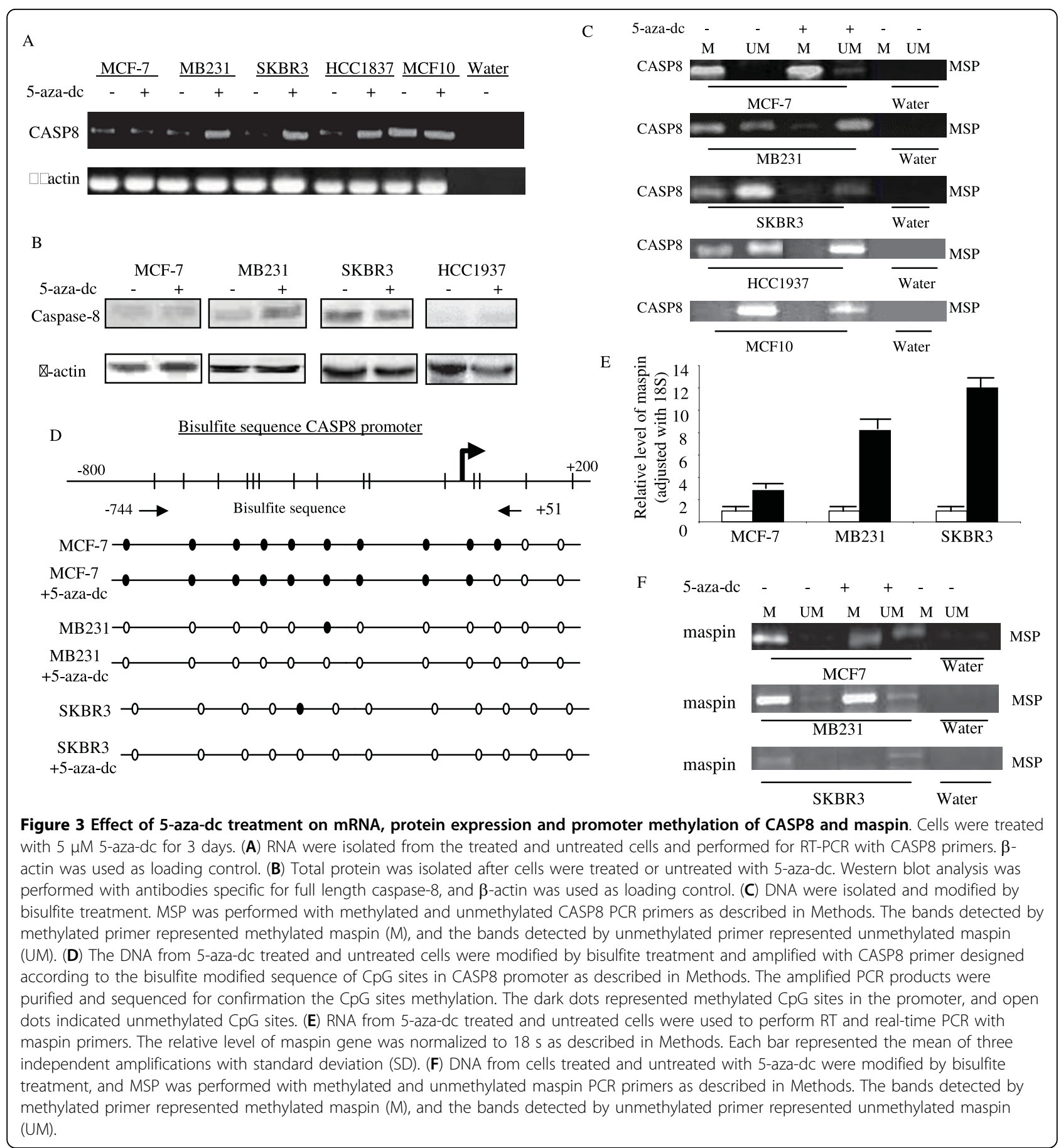

addition, DNMT1 was not inhibited by 5 -aza-dc in all three breast cancer cells tested.

\section{CHIP Assay to determine the specificity of CASP8} demethylation in response to 5 -aza-dc

DNA methyltransferase inhibitors commonly used in clinical trials promote tumor cell death, but their detailed cytotoxic action is not yet fully understood. A deeper knowledge about their apoptosis-inducing mechanisms and their interaction with DNA methyltransferases (DNMTs) DNMT1, DNMT3a, and DNMT3b might allow the design of more effective drugs with lower cytotoxicity. 5-aza-deoxycytidine (5aza-dc), a potent inhibitor of DNMT1, is known to induce demethylation and reactivation of silenced genes. Our data suggest that 5 -aza-dc treatment increases CASP8 transcription in MB231, SKBR3 and BT474, but 
A

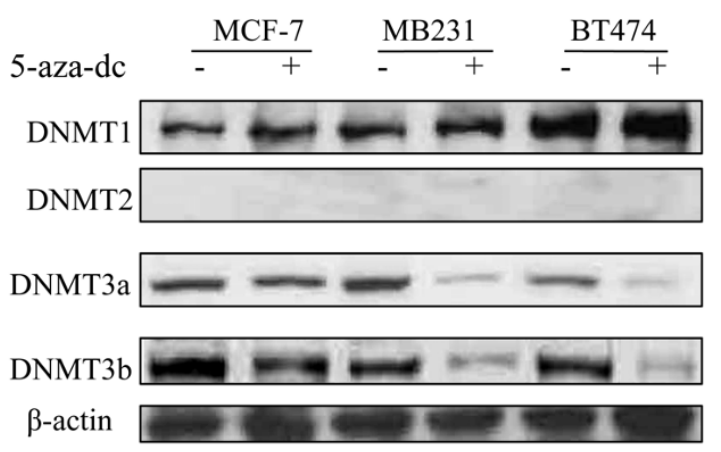

$\mathrm{B}$
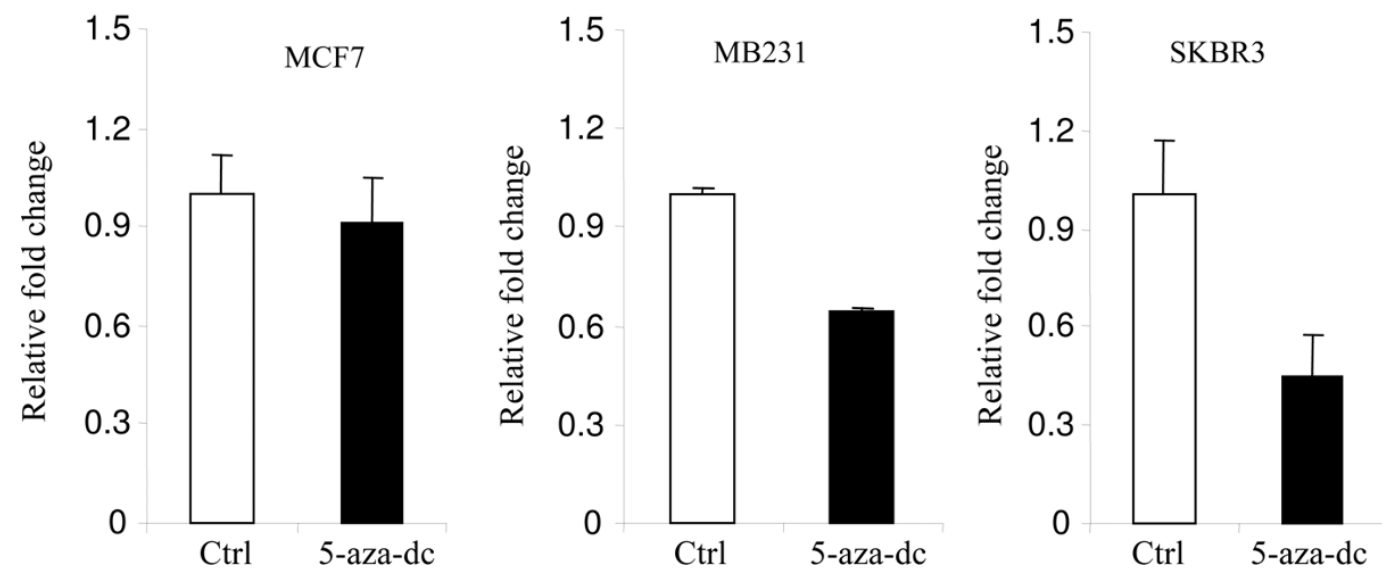

Figure 4 Effect of 5-aza-dc on DNMTs, and H3K9me2. (A) Total protein from the 5-aza-dc treated and untreated cells was used to perform Western blot analysis with antibodies specific against DNMT1, DNMT2, DNMT3a and DNMT3b as described in Methods. Antibody against $\beta$-actin was also used as loading control. (B) Chromatins were extracted from cells with or without 5-aza-dc treatment as described in Methods. Chromatin immunoprecipitation was performed with antibody specific against histone H3K9me2, and recovered DNA fragments were used for Q-PCR with promoter specific primers of CASP8. Fold change of H3K9me2 occupancy was calculated based on the control (without 5-aza-dc treatment). Each bar represented the mean of three independent amplifications with standard deviation (SD).

not in MCF-7 cells. Recent studies indicate that histone H3 lysine methylation represses gene transcription $[16,17]$. Thus, we further investigated whether 5 -aza-dc reduces histone $\mathrm{H} 3$ methylation to activate CASP8 transcription in breast cancer cells. Our results (Figure 4B) show that 5-aza -dc inhibits H3K9me2 occupancy on CAPS8 promoter in SKBR3 and MB231, but not in MCF-7 cells lines. These results suggest that CASP 8 gene transcription is restored in theses SKBR3 and MB231, but not in MCF-7 cells.

\section{Effect of inhibiting HDAC with TSA}

Histone deacetylation is an important mechanism of regulation of gene expression. Since MCF-7 cells treatment with 5-aza-dc did not increase the levels of CASP8 gene and protein expression, we also investigated whether treatment of MCF-7 cells with TSA (Trichostatin A), inhibitor of histone deacetylase (HDAC), in combination with 5-aza-dc could change the methylation status of CASP8 and alter the gene and protein expression. As shown in Figure 5A, MCF-7 treated with TSA $(0.3 \mu \mathrm{M}$ for 2 days $)$ in combination with 5 -aza-dc partially demethylated CASP 8 promoter. The mRNA level of CASP8 was significantly increased (Figure 5B), and the cleaved caspase- 8 protein could be seen in cells treated with TSA in combination with 5-aza expression (Figure 5C). Consistent with the mRNA and protein data, TSA in combination with 5-aza-dc treatment significantly reduced Di-Methylated Histone H3 (Lys27) and increased Acetylated Histone H3 (Lys9), as shown in Figure 5D.

\section{Effect of 5-Fu on CASP8}

Recent studies have shown that the anticancer drug, 5fluorouracil (5-Fu), can upregulate CASP8 protein and induce cell apoptosis in leukemia and breast cancer cells 


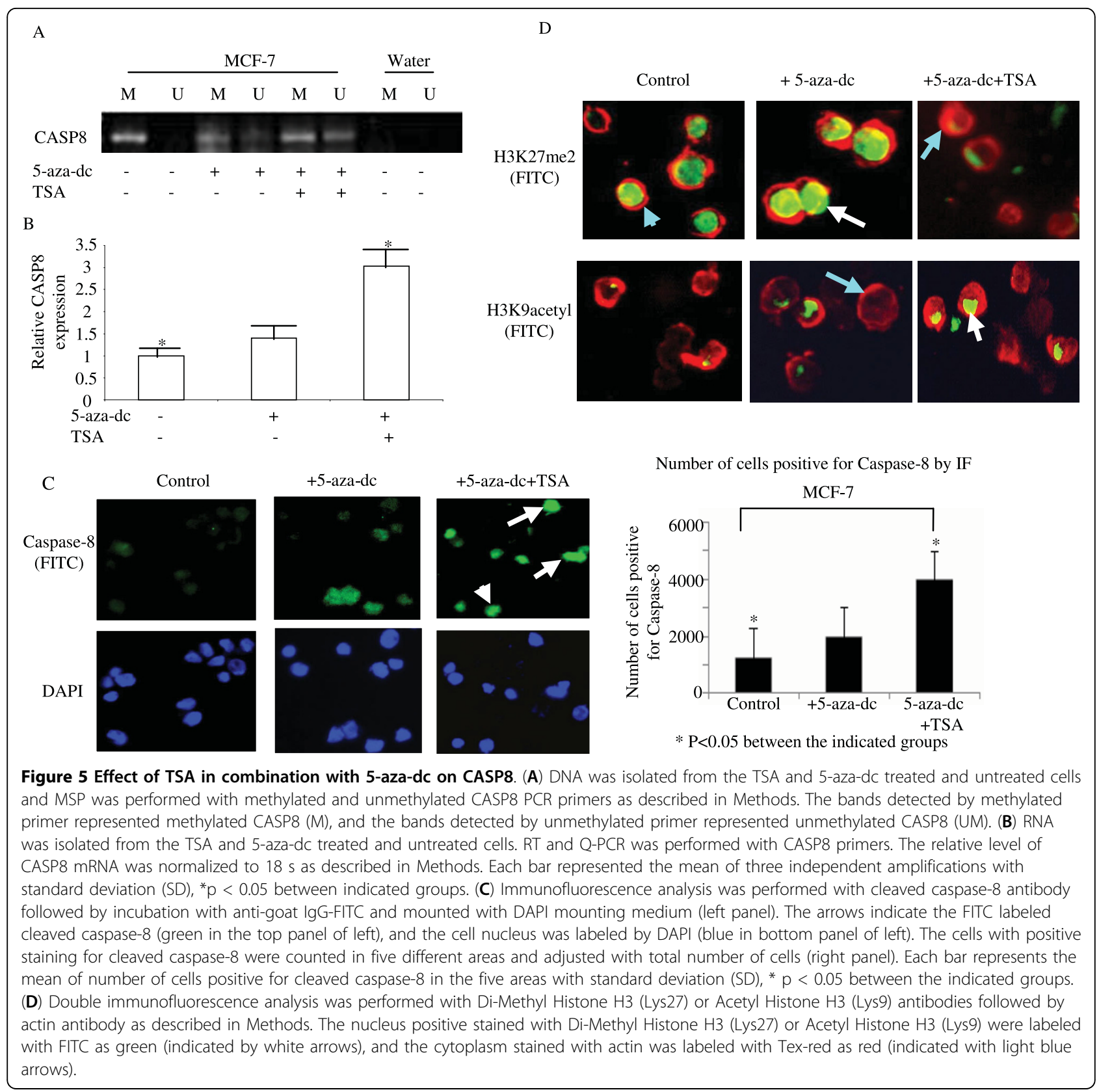

[18,19]. 5-Fu has been successfully used for treatment of breast cancer in clinical practice. We examined if 5 - Fu treatment could upregulate CASP8 in breast cancer and if the upregulation involved demethylating CpG sites on CASP8 promoter. As shown earlier, CASP8 mRNA was undetectable in MCF-7 breast cancer cells due to promoter methylation. We then treated MCF-7 cells with 5-Fu for 3 days and examined CASP8 mRNA levels. Figure $6 \mathrm{~A}$ shows almost 4 fold increase in mRNA level in MCF-7 cells treated with 5-Fu compared to non-treated cells. The mRNA level of CASP8 in MB231 and SKBR3 treated with 5-Fu also increased 2.4 fold and 1.8 fold respectively (Figure 6A). The increases in mRNA expression are correlated with partial demethylation of CpG sites on CASP8 promoter (Figure 6B). Bisulfite sequencing confirmed the position (nt -642 to nt -532 , located in CASP8 core promoter region) of demethylation of CASP promoter by 5 -Fu in these breast cancer cells (Figure 6C).

\section{Discussion}

Hypermethylation of the promoter regions of various genes has been recognized as one of the most frequent mechanisms causing loss of gene function. The 


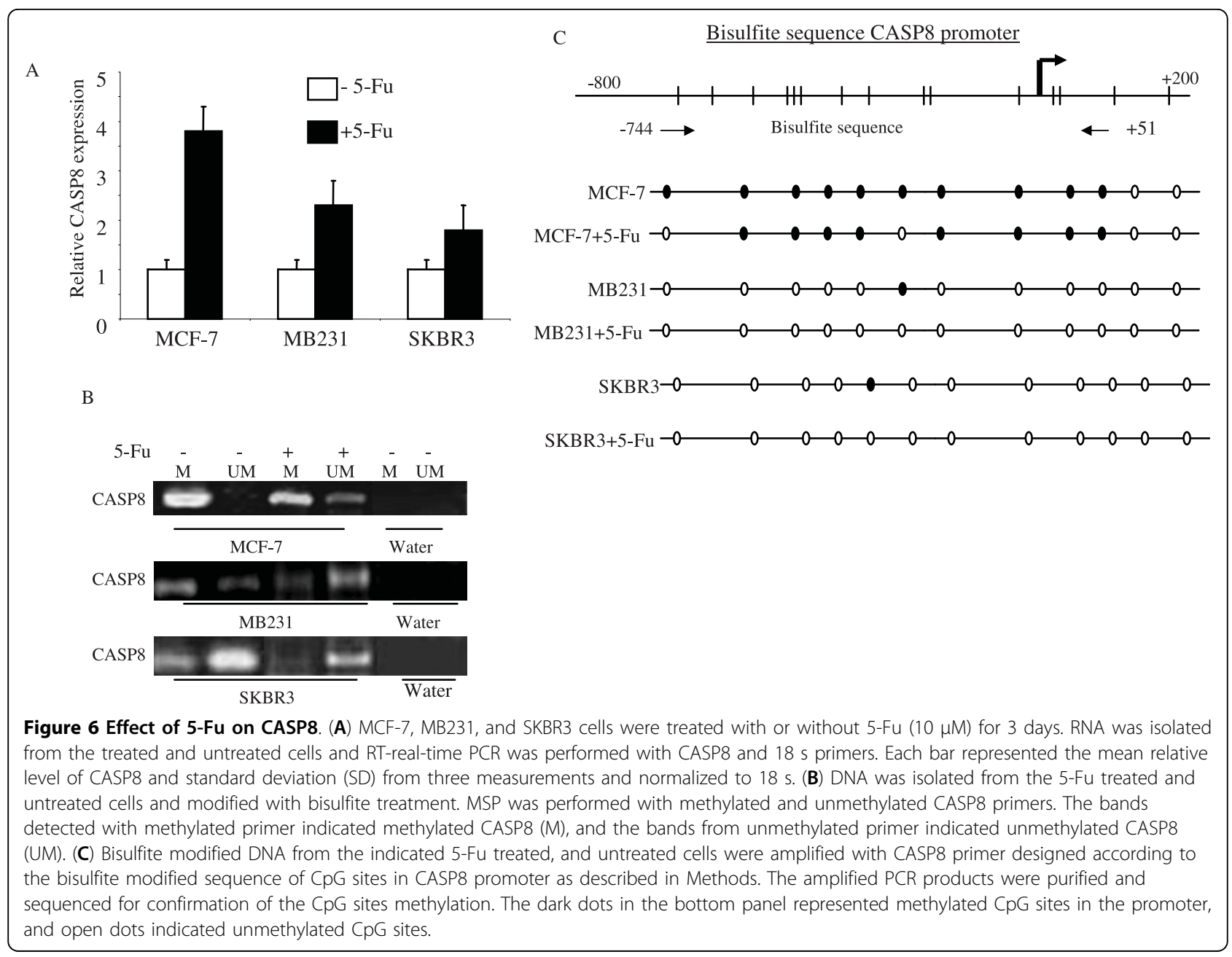

association between aberrant DNA methylation and carcinogenesis has been demonstrated in several studies [20-26]. However, the association between epigenetic changes with cancer etiology needs to be elucidated.

Several cancer-related genes have been reported to be silenced by aberrant methylation in breast cancer, such as 14-3-3 s, E-cadherin and tissue inhibitor of metalloproteinase 3 (TIMP3) genes. Treatment with 5 -aza-dc activated the expression of 14-3-3 s [27] and E-cadherin genes [28] in breast carcinoma cells and of TIMP3 in different tumor cell lines [29,30].

Hypermethylation of CASP8 has been showed as a frequent feature of relapsed glioblastoma compared with the corresponding primary tumors [31]. The authors suggested that epigenetic deregulation of the mitochondria-independent apoptosis is a relevant characteristic in recurrent glioblastoma. The development of targeted therapies restoring functional extrinsic apoptosis, as recently shown in vivo with the synergistic combination of the DNA demethylating agent decitabine and TRAIL [32], may provide a useful tool to overcome the resistance of glioblastoma to contemporary treatment modalities. Methylation of CASP8 gene has also been reported in some childhood tumors and in neuroendocrine lung tumors [33]. CASP8 is an important initiator of apoptosis [10]. Structurally, the promoter region of CASP8 has binding sites for $\mathrm{p} 53$, nuclear factor- $\kappa \mathrm{B}$ (NF$\kappa \mathrm{B}), \mathrm{AP}-1, \mathrm{SP}-1, \mathrm{IRF}-1$, and Ets-like transcription factors [34]. Therefore, CASP8 functions both as a pivotal molecule for death-receptor-induced apoptosis and as a selective signal transducer, such as for NF- $\kappa \mathrm{B}$ activation [35]. Absent or downregulation of CASP8 could cause resistance to apoptosis and is correlated with unfavorable disease outcome, such as in childhood medulloblastoma and neuroblastoma $[11,12]$. Others have also demonstrated that absence or downregulation of CASP8 may be due to epigenetic changes, such as hypermethylation, or mutations [36,37].

In current study we have investigated the promoter methylation of CASP8 and maspin in relation to their expression levels as well as the involvement of histone methyltransferases and histone H3K9me2. Using MSP 
and bisulfite sequence analysis, we have established the relationship between aberrant cytosine methylation and downregulated or loss of CASP8 in breast cancer cells. We confirmed that CpG sites methylation in the promoter region of CASP8 is the mechanistic basis for transcriptional downregulation or silencing of CASP8 in breast cancer cells. The methylation status of CASP8 can be completely or partially reversed by treatment with 5-aza-dc in MB231, SKBR3, and BT474, but not in MCF-7 breast cancer cells. The cells that had fewer methylated CpG sites, such as MB231 and SKBR3 were totally demethylated by 5 -aza-dc. This change in demethylation resulted in a significant increase in CASP 8 mRNA and protein expression. In contract SKBR3 cells, most CpG sites of CASP8 were methylated in MCF-7 cells. Results from MSP showed that methylation was partially reversed by 5 -aza-dc in MCF-7 cells and the mRNA and protein level of CASP8 had no significant increase. We also examined the effect of histone acetylation of CASP8 by treating MCF-7 cells with Trichostatin A (TSA). The TSA treatment alone did not change the methylation status and mRNA expression of CASP8 in MCF-7 cells (data not shown). However, TSA in combination with 5 -aza-dc was able to partially demethylate CASP8 promoter and increased CASP8 mRNA and protein expression in MCF-7 cells. The data suggested the involvement of histone acetylation in the regulation of CASP8 gene expression in MCF-7 cells. CHIP analysis (Figure 4B) showed that 5-aza-dc treatment inhibits H3K9me2 occupancy on CAPS8 promoter in SKBR3 and MDA-MB231, but not in MCF-7 cells. These results suggest that CASP8 gene transcription is restored in theses SKBR3 and MB231, but not in MCF7 cells.

Several studies have demonstrated a link between methylation and histone acetylation in which a family of methyl-CpG-binding proteins is involved [38]. When these proteins bind to a methylated promoter, they recruit HDAC, and the interaction of these two epigenetic events inhibits gene expression by interfering with the function of transcription factors and the compaction of the chromatin structure [39-41]. Inhibitors of these epigenetic changes can lead to the reactivation of genes that suppress tumorigenesis. In accord with this hypothesis is the report on the synergistic interaction of 5-azadc and the HDAC inhibitor, trichostatin A (TSA), in the reactivation of tumor suppressor genes [42]. This same drug combination was also reported to induce a synergistic reactivation of the estrogen receptor- $\alpha$ in breast carcinoma cells [43].

A recent study in prostate cancer cells indicated that CASP8 plays a pathway specific role in inhibiting androgen receptor signaling [44]. This evidence suggests that CASP8 may have the role beyond its role as a cell death protease and may play a role in hormonal receptor cell signaling.

The anticancer drug, fluorouracil (5-Fu), has been commonly used in clinical practice for first line treatment of breast cancer for decades. Up to now, except for interferon- $\gamma$ and azacytidine, the cytotoxic drugs, 5$\mathrm{Fu}$ and methotrexate, have been shown to upregulate CASP8 and induce cell apoptosis in neuroblastoma, medulloblastoma, Ewing sarcoma, glioblastoma, leukemia, and breast cancer cells $[18,19]$. The mechanism by which 5-Fu regulates CASP8 protein is more likely to involve p53 [19]. However, studies from Zoli, et al. [18] suggest that 5 -Fu in combination with doxorubicin and paclitaxel regulates CASP8 and induces cell apoptosis by a caspase-dependent mechanism independent of hormonal, p53, bcl-2 or bax status in breast cancer cells [18]. These observations made us to suspect that 5 -Fu induced cell apoptosis may involve a demethylation process. We then tested the expression CASP8 mRNA, as well as its methylation status, in MCF-7, MB231 and SKBR3 cells treated with 5 -Fu for 3 days. Compared to untreated cells, the cells treated with 5 -Fu showed a significant increase mRNA expression of CASP8 followed by demethylation of its promoter region.

Taken together, our results confirm that expression of CASP8 in breast cancer is epigenetically controlled and the modification may vary in different types of breast cancer cells.

Another gene promoter methylation has been studied was maspin in current study. Maspin belongs to the serpin family [45]. It acts as a tumor suppressor, increases cell adhesion, induces apoptosis, and inhibits tumor growth and metastasis [46-48]. Maspin is also involved in angiogenesis and mammary gland development [49]. The expression of maspin is epigenetically controlled by methylation and/or histone acetylation. Studies have also indicated that methylation and demethylation of maspin promoter may regulate maspin gene expression and that reduced maspin expression is associated with cancer progression [13]. In our study, we have confirmed that the expression of maspin in breast cancer cells is epigenetically controlled by methylation of the $\mathrm{CpG}$ sites. The demethylation agent, 5-aza-dc, treatment reversed maspin promoter methylation and increased maspin gene expression in MCF-7, MB231, and SKBR3 cells. An early study from Domann FE et al. [50] also reported that normal human mammary epithelial cells expressed maspin mRNA and displayed a completely non-methylated maspin gene promoter. In contrast, most breast cancer cell lines had no detectable maspin expression and those maspin-negative breast cancer cell lines also displayed an aberrant pattern of cytosine methylation of the maspin promoter. In this study we have also examined maspin and CASP8 mRNA levels in 
30 breast cancer tissues and 10 non-breast cancer tissues. The mRNA levels of CASP8 and maspin were lower in breast cancer tissue than non-breast cancer tissue (data not shown). The decreased mRNA expressing levels of maspin and CASP8 in patients were associated with positive lymph node status, late stage disease, and HER2 overexpression (3+ and/or FISH positive). The DFS was significant decreased in patients with low CASP8 or maspin expression (data not shown). Inactivation of apoptotic pathways is often critical for the pathogenesis of tumor cells and for their resistance to chemotherapeutic drug treatment and/or irradiation [51-53]. It needs to be determined if the loss of CASP8 and/or maspin expression can be a prognostic marker for Breast Cancer and if it is associated with amplification of MYCN ( $\mathrm{v}$-myc myelocytomatosis viral related oncogene), as frequently observed in neuroblastomas.

Limitations of this study are that the most investigation was used cell lines only. To better understand the clinical relevance of CASP8 and/or maspin promoter methylation in breast tumors and if the decreased mRNA expression of CASP8 and/or maspin were correlated to the aberrant pattern of cytosine methylation of the gene promoter further studies with large sample size should be conducted.

\section{Conclusions}

In conclusion, our results show that methylation of $\mathrm{CpG}$ sites at the promoter region in certain genes, such as CASP8 and maspin, could result in transcriptional downregulation or silencing of genes and protein in breast cancer cells. The anticancer drug, $5-\mathrm{Fu}$, is able to upregulate CASP8 gene expression, and the mechanism may involve demethylation. Screening promoter methylation patterns in breast cancer patients could be an important step to develop treatment protocols that target the methylated gene and improve DFS in breast cancer patients. Future studies also should examine the use of non-toxic demthylating agents in combination with chemotherapeutic drugs would offer an advantage for the treatment of breast cancer patients.

Additional file 1: Figure S1. Promoter CpG sites of CASP8 and maspin and the primers sequences covered regions. A figure to show the primers sequences used for MSP and bisulfate sequence covered regions in CASP8 promoter. Figure Legend for Figure S1. Click here for file

[http://www.biomedcentral.com/content/supplementary/1471-2407-1032-S1.PPT]

\section{Abbreviations}

CASP8: Caspase 8; DNMT: DNA Methyltransferase; MSP: Methylated Specific Primer; 5-azadc: 5-aza-2'-deoxycytidine; TSA: Trichostatin A; HDAC: H; 5-Fu: 5Fluorouracil; ATCC: American Type Culture Collection (Manassas, VA, USA); ER: estrogen receptor; IHC: Immunohistochemistry

\section{Acknowledgements}

This work received financial support from the following sources: $\mathrm{NIH} / \mathrm{NCl}$ U54 CA14393-01 (JW); U56 CA101599-01 (JW), CA15083-25S3 (JW), NIH/ NIDDK R25 DK067015-01 (JW), Department of Defense (BCRP) BC043180 (JW), and MBRS NIH SO6 GM0685-10-01 (YW).

\section{Author details}

'Division of Cancer Research and Training, Department of Internal Medicine, Charles R. Drew University of Medicine and Science, (1731 East 120th Street) Los Angeles, CA (90059), USA. ²Division of Hematology/Oncology, Department of Internal Medicine, David Geffen UCLA School of Medicine, CA (5535 Macdonald Research Laboratories Building, 675 Charles E. Young Drive South), Los Angeles, CA (90095), USA. ${ }^{3}$ Division of Hematology/ Oncology, Department of Internal Medicine, Cedars-Sinai Medical Center, (8700 Beverly Blvd., Suite 6215), Los Angeles, CA (90048), USA.

\section{Authors' contributions}

YW, MA and JW were responsible for data collection, analysis, manuscript preparation, and editing. HPK and DS critical review and were involved in study design. All authors read and approved the final manuscript.

\section{Competing interests}

The authors declare that they have no competing interests.

Received: 1 July 2009

Accepted: 4 February 2010 Published: 4 February 2010

\section{References}

1. Chiang PK, Gordon RK, Tal J, Zeng GC, Doctor BP, Pardhasaradhi K, McCann PP: S-Adenosylmethionine and methylation. FASEB J 1996, 10:471-480.

2. Baylin SB, Herman JG, Graff JR, Vertino PM, Issa JP: Alterations in DNA methylation: a fundamental aspect of neoplasia. Adv Cancer Res 1998, 72:141-196.

3. Yang $X$, Yan L, Davidson NE: DNA methylation in breast cancer. Endocr Relat Cancer 2001, 8:115-127.

4. Widschwendter $\mathrm{M}$, Jones PA: DNA methylation and breast carcinogenesis. Oncogene 2002, 21:5462-5482.

5. Miyakura Y, Sugano K, Konishi F, Ichikawa A, Maekawa M, Shitoh K, Shitoh K, Igarashi S, Kotake K, Koyama Y, Nagai H: Extensive methylation of hMLH1 promoter region predominates in proximal colon cancer with microsatellite instability. Gastroenterology 2001, 121:1300-1309.

6. Ricciardiello L, Goel A, Mantovani V, Fiorini T, Fossi S, Chang DK, Lunedei V, Pozzato P, Zagari RM, De Luca L, Fuccio L, Martinelli GN, Roda E, Boland CR, Bazzoli F: Frequent loss of hMLH1 by promoter hypermethylation leads to microsatellite instability in adenomatous polyps of patients with a single first-degree member affected by colon cancer. Cancer Res 2003, 63:787-792.

7. Press JZ, De Luca A, Boyd N, Young S, Troussard A, Ridge Y, Kaurah P, Kalloger SE, Blood KA, Smith M, Spellman PT, Wang Y, Miller DM, Horsman D, Faham M, Gilks CB, Gray J, Huntsman DG: Ovarian carcinomas with genetic and epigenetic BRCA1 loss have distinct molecular abnormalities. BMC Cancer 2008, 8:17.

8. Wei M, Xu J, Dignam J, Nanda R, Sveen L, Fackenthal J, Grushko TA, Olopade OI: Estrogen receptor alpha, BRCA1, and FANCF promoter methylation occur in distinct subsets of sporadic breast cancers. Breast Cancer Res Treat 2008, 111:113-120.

9. Fiegl H, Millinger S, Goebel G, Müller-Holzner E, Marth C, Laird PW, Widschwendter M: Breast cancer DNA methylation profiles in cancer cells and tumor stroma: association with HER-2/neu status in primary breast cancer. Cancer Res 2006, 66:29-33.

10. Salvesen GS: Caspase-8: igniting the death machine. Structure 1999, 7: R225-229.

11. Pingoud-Meier $C$, Lang $D$, Janss AJ, Rorke LB, Phillips PC, Shalaby $T$, Grotzer MA: Loss of caspase-8 protein expression correlates with unfavorable survival outcome in childhood medulloblastoma. Clin Cancer Res 2003, 9:6401-6409.

12. Yang $Q$, Kiernan $C M$, Tian $Y$, Salwen HR, Chlenski A, Brumback BA London WB, Cohn SL: Methylation of CASP8, DCR2, and HIN-1 in neuroblastoma is associated with poor outcome. Clin Cancer Res 2007, 13:3191-3197. 
13. Khalkhali-Ellis Z: Maspin: the new frontier. Clin Cancer Res 2006 12:7279-7283.

14. Li LC, Dahiya R: MethPrimer: designing primers for methylation PCRs. Bioinformatics 2002, 18:1427-1431.

15. Kuo $\mathrm{M}-\mathrm{H}$, Allis $\mathrm{CD}$ : In vivo cross-linking and immunoprecipitation for studying dynamic protein:DNA associations in a chromatin environment. Methods 1999, 19:425-433.

16. Trojer $P$, Reinberg $D$ : Histone lysine demethylases and their impact on epigenetics. Cell 2006, 125:213-217.

17. Lan F, Bayliss PE, Rinn JL, Whetstine JR, Wang JK, Chen S, Iwase S, Alpatov R, Issaeva I, Canaani E, Roberts TM, Chang HY, Shi Y: A histone H3 lysine 27 demethylase regulates animal posterior development. Nature 2007, 449:689-694.

18. Zoli W, Ulivi P, Tesei A, Fabbri F, Rosetti M, Maltoni R, Giunchi DC, Ricotti L, Brigliadori G, Vannini I, Amadori D: Addition of 5-fluorouracil to doxorubicin-paclitaxel sequence increases caspase-dependent apoptosis in breast cancer cell lines. Breast Cancer Res 2005, 7:R681-689.

19. Ehrhardt H, Häcker S, Wittmann S, Maurer M, Borkhardt B, Toloczko A, Debatin KM, Fulda S, Jeremias I: Cytotoxic drug-induced, p53-mediated upregulation of caspase-8 in tumor cells. Oncogene 2008, 27:783-793.

20. Barton CA, Hacker NF, Clark SJ, O'Brien PM: DNA methylation changes in ovarian cancer: Implications for early diagnosis, prognosis and treatment. Gynecol Oncol 2008, 109:129-139.

21. Dobosy JR, Roberts JL, Fu VX, Jarrard DF: The expanding role of epigenetics in the development, diagnosis and treatment of prostate cancer and benign prostatic hyperplasia. J Urol 2007, 177:822-831.

22. Yuan J, Luo RZ, Fuji S, Wang L, Hu W, Andreeff M, Pan Y, Kadota M, Oshimura M, Sahin AA, Issa JP, Bast RC Jr, Yu Y: Aberrant methylation and silencing of $\mathrm{ARHI}$, an imprinted tumor suppressor gene in which the function is lost in breast cancers. Cancer Res 2003, 63:4174-4180.

23. Chen K, Sawhney R, Khan M, Benninger MS, Hou Z, Sethi S, Stephen JK, Worsham MJ: Methylation of multiple genes as diagnostic and therapeutic markers in primary head and neck squamous cell carcinoma. Arch Otolaryngol Head Neck Surg 2007, 133:1131-1138.

24. Ellinger J, El Kassem N, Heukamp LC, Matthews S, Cubukluoz F, Kahl P, Perabo FG, Müller SC, von Ruecker A, Bastian PJ: Hypermethylation of cellfree serum DNA indicates worse outcome in patients with bladder cancer. J Urol 2008, 179:346-352.

25. Park do Y, Sakamoto H, Kirley SD, Ogino S, Kawasaki T, Kwon E, MinoKenudson M, Lauwers GY, Chung DC, Rueda BR, Zukerberg LR: The Cables gene on chromosome $18 \mathrm{q}$ is silenced by promoter hypermethylation and allelic loss in human colorectal cancer. Am J Pathol 2007, 171:1509-1519.

26. Henken FE, Wilting SM, Overmeer RM, Rietschoten JG, Nygren AO, Errami A, Schouten JP, Meijer CJ, Snijders PJ, Steenbergen RD: Sequential gene promoter methylation during HPV-induced cervical carcinogenesis. $\mathrm{Br} J$ Cancer 2007, 97:1457-1464.

27. Ferguson AT, Evron E, Umbricht CB, Pandita TK, Chan TA, Hermeking $H$, Marks JR, Lambers AR, Futreal PA, Stampfer MR, Sukumar S: High frequency of hypermethylation at the 14-3-3 s locus leads to gene silencing in breast cancer. Proc Natl Acad Sci USA 2000, 97:6049-6054.

28. Graff JR, Herman JG, Lapidus RL, Chopra H, Xu R, Jarrard DF, Isaacs WB, Pitha PM, Davidson NE, Baylin SB: E-cadherin expression is silenced by DNA hypermethylation in human breast and prostate carcinomas. Cancer Res 1995, 55:5195-5199.

29. Bachman KE, Herman JG, Corn PG, Merlo A, Costello JF, Cavenee WK, Baylin SB, Graff JR: Methylation-associated silencing of the tissue inhibitor of metalloproteinase-3 gene suggest a suppressor role in kidney, brain, and other human cancers. Cancer Res 1999, 59:798-802.

30. Cameron EE, Bachman KE, Myohanen S, Herman JG, Baylin SB: Synergy of demethylation and histone deacetylase inhibition in the re-expression of genes silenced in cancer. Nat Genet 1999, 21:103-107.

31. Martinez $R_{-}$, Setien F, Voelter C, Casado S, Quesada MP, Schackert G, Esteller M: CpG island promoter hypermethylation of the pro-apoptotic gene caspase- 8 is a common hallmark of relapsed glioblastoma multiforme. Carcinogenesis 2007, 28:1264-1268.

32. Eramo A, Pallini R, Lotti F, Sette G, Patti M, Bartucci M, Ricci-Vitiani L, Signore M, Stassi G, Larocca LM, Crinò L, Peschle C, De Maria R: Inhibition of DNA Methylation Sensitizes Glioblastoma for Tumor Necrosis FactorRelated Apoptosis-Inducing Ligand-Mediated Destruction. Cancer Research 2005, 65:11469-11477.
33. Harada K, Toyooka S, Shivapurkar N, Maitra A, Reddy JL, Matta H, Miyajima K, Timmons CF, Tomlinson GE, Mastrangelo D, Hay RJ, Chaudhary PM, Gazdar AF: Deregulation of caspase 8 and 10 expression in pediatric tumors and cell lines. Cancer Res 2002, 62:5897-5901.

34. Liedtke C, Groger N, Manns MP, Trautwein C: The human caspase-8 promoter sustains basal activity through SP1 and ETS-like transcription factors and can be upregulated by a p53-dependent mechanism. J Biol Chem 2003, 278:27593-27604.

35. Chaudhary PM, Eby MT, Jasmin A, Kumar A, Liu L, Hood L: Activation of the NF-kappaB pathway by caspase- 8 and its homologs. Oncogene 2000, 19:4451-4460

36. Teitz T, Wei T, Valentine MB, Vanin EF, Grenet J, Valentine VA, Behm FG, Look AT, Lahti JM, Kidd VJ: Caspase-8 is deleted or silenced preferentially in childhood neuroblastomas with amplification of MYCN. Nat Med 2000, 6:529-535

37. Fulda S, Debatin KM: IFNgamma sensitizes for apoptosis by upregulating caspase-8 expression through the Stat1 pathway. Oncogene 2002, 21:2295-2308

38. Magdinier F, Wolffe AP: Selective association of the methyl-CpG binding protein MBD2 with the silent p14/p16 locus in human neoplasia. Proc Natl Acad Sci USA 2001, 98:4990-4995.

39. Nan $\mathrm{X}, \mathrm{Ng} \mathrm{HH}$, Johnson CA, Laherty CD, Turner BM, Eisenman RN, Bird A: Transcriptional repression by the methyl-CpG-binding protein MeCP2 involves a histone deacetylase complex. Nature 1998, 393:386-389.

40. Jones PL, Veenstra GJ, Wade PA, Vermaak D, Kass SU, Landsberger N, Strouboulis J, Wolffe AP: Methylated DNA and MeCP2 recruit histone deacetylase to repress transcription. Nat Genet 1998, 19:187-191.

41. Jones PA, Baylin SB: The fundamental role of epigenetic events in cancer. Nat Genet 2002, 3:415-428.

42. Cameron EE, Bachman KE, Myohanen S, Herman JG, Baylin SB: Synergy of demethylation and histone deacetylase inhibition in the re-expression of genes silenced in cancer. Nat Genet 1999, 21:103-107.

43. Yang X, Phillips DL, Ferguson AT, Nelson WG, Herman JG, Davidson NE: Synergistic activation of functional estrogen receptor (ER)-a by DNA methyltransferase and histone deacetylase inhibition in human ER-a negative breast cancer cells. Cancer Res 2001, 61:7025-7029.

44. Qi W, Wu H, Yang L, Boyd DD, Wang Z: A novel function of caspase-8 in the regulation of androgen-receptor-driven gene expression. EMBO 2007, 26:65-75.

45. Bailey CM, Khalkhali-Ellis Z, Seftor EA, Hendrix MJ: Biological functions of maspin. J Cell Physiol 2006, 209:617-624.

46. Zhang W, Shi HY, Zhang M: Maspin overexpression modulates tumor cell apoptosis through the regulation of $\mathrm{Bcl}-2$ family proteins. BMC Cancer 2005, 5(50)

47. Sheng S: The promise and challenge toward the clinical application of maspin in cancer. Front Biosci 2004, 9:2733-2745.

48. Odero-Marah VA, Khalkhali-Ellis Z, Chunthapong J, Amir S, Seftor RE, Seftor EA, Hendrix MJ: Maspin regulates different signaling pathways for motility and adhesion in aggressive breast cancer cells. Cancer Biol Ther 2003, 2:398-403.

49. Zhang $M$, Volpert $\mathrm{O}$, Shi $\mathrm{YH}$, Bouck N: Maspin is an angiogenesis inhibitor. Nat Med 2000, 6:196-199.

50. Domann FE, Rice JC, Hendrix MJ, Futscher BW: Epigenetic silencing of maspin gene expression in human breast cancers. Int J Cancer 2000, 85:805-810.

51. Rinkenberger $\mathrm{J}$, Korsmeyer $\mathrm{SJ}$ : Errors of homeostasis and deregulated apoptosis. Curr Opin Genet Dev 1997, 7:589-596.

52. Reed JC: Mechanisms of apoptosis avoidance in cancer. Curr Opin Oncol 1999, 11:58-75.

53. Lowe SW, Lin AW: Apoptosis in cancer. Carcinogenesis 2000, 21:485-495

\section{Pre-publication history}

The pre-publication history for this paper can be accessed here:http://www biomedcentral.com/1471-2407/10/32/prepub

doi:10.1186/1471-2407-10-32

Cite this article as: Wu et al:: Caspase 8 and maspin are downregulated in breast cancer cells due to $\mathrm{CpG}$ site promoter methylation. $B M C$ Cancer 2010 10:32. 